\title{
Introduction
}

\section{Anticipatory Imaginaries: Dialogues between academic research and the creative imagination}

\author{
Marcus Bussey, Lisa Chandler, Gary Crew, and Rachel Robertson
}

The future isn't what it used to be, that's for sure. Eminent futurist Ziauddin Sardar summed up the situation under the banner of postnormal times. Here, in true Dickensian manner, he lays out the crisis for us:

\begin{abstract}
Welcome to postnormal times. It's a time when little out there can be trusted or gives us confidence. The espiritu del tiempo, the spirit of our age, is characterised by uncertainty, rapid change, realignment of power, upheaval and chaotic behaviour. We live in an in-between period where old orthodoxies are dying, new ones have yet to be born, and very few things seem to make sense. Ours is a transitional age, a time without the confidence that we can return to any past we have known and with no confidence in any path to a desirable, attainable or sustainable future. It is a time when all choices seem perilous, likely to lead to ruin, if not entirely over the edge of the abyss. In our time it is possible to dream all dreams of visionary futures but almost impossible to believe we have the capability or commitment to make any of them a reality. We live in a state of flux beset by indecision: what is for the best, which is worse? We are disempowered by the risks, cowed into timidity by fear of the choices we might be inclined or persuaded to contemplate (2010 p. 435).
\end{abstract}

There is a certain swagger to all this where cliché trumps common sense. We are regularly told that calamity is upon us and the popular imagination is drawn towards futures of diminishing returns. Yet we must remember that it was 1859 when Dickens wrote his lyrically rhetorical lines:

It was the best of times, it was the worst of times, it was the age of wisdom, it was the age of foolishness, it was the epoch of belief, it was the epoch of incredulity, it was the season of Light, it was the season of Darkness, it was the spring of hope, it was the winter of despair, we had everything before us, we had nothing before us, we were all going direct to Heaven, we were all going direct the other way... (1859 p. 1).

The state of the future seemed as dire then as it does now and Dickens makes this point too. The prophets of doom have spoiled it for those amongst us who seek to explore and imagine a range of possibilities; who undertake rigorous scientific enquiry, write penetrating analyses of political, environmental, historical, social and economic issues and generally seek to make the world intelligible. Furthermore, our thinking about the future has been colonised by images that reduce agency and are leading to denial, techno-salvationism or apathy.

In this climate of contestation and uncertainty it is easy to pay undue attention to the tide of scepticism around climate change and scientific claims in general, but the reality is that science and, more broadly speaking, expert knowledge is not reaching those who need to hear it. Those preaching 'sense' in a postnormal world are preaching to people who, for better or worse, appear to be deaf. George Lakoff argues that this is because people do not have the required conceptual and emotional frames to receive expert information: that the 'sensible' for one person is not necessarily the 'sensible' for another. This is, in part, a language game, but more deeply it is a question of 'frames' which carry emotional queues on how to respond to information. As Lakoff puts it: 
...when you are arguing against the other side: Do not use their language. Their language picks out a frame - and it won't be the frame you want (2005 p. 3).

This special issue is interested in the language possibilities inherent to this reframing and proposes that there are multiple languages or frames through which we can envisage and understand possible futures. It presents expert knowledge alongside creative expression to stimulate a range of dialogical possibilities that expert and creative expression, on their own, cannot achieve. We, the editors, argue that any engagement with our present, in the light of the future, calls upon an anticipatory aesthetic (Bussey 2017a, 2017b) in which the imagination is a key producer of foresight, hope and a range of possibilities.

Anticipatory imaginaries are 'futures oriented creative spaces in the present' where societies do the work of maintaining and constructing their identities (see: Castoriadis 1997 pp. 3-18). Such approaches counter the feelings of disempowerment and the incapacity to make choices that Sardar argues are defining features of post-normal times. Consequently, we are more interested in what Ricatti (2013) refers to as the "emotion of truth', rather than with 'empirical truths'. We argue with Ricatti:

...that truth, as experienced by humans, shares many of the characteristics associated with emotions: it is expressed and performed, it has a cognitive value but cannot be reduced only to its cognitive function, and it is a matter of and a tool for contested discourses, performances and artworks (2013 p.128).

That truth and emotions are closely linked suggests that there are opportunities inherent to creative processes that deliberately mess with the cosmetic distinction between truth and our emotional attachment to given frames. Expression and performance, therefore, become contexts in which alternatives can be explored. So, to this end, in this special edition of TEXT we have gathered a set of dialogical reflections on issues that are contributing to the uncertainty and anxiety of post-normal times. Collectively, the contributions employ an 'anticipatory imaginaries' approach by exploring a series of creative and collective spaces. These are comprised of eight scholarly provocations related to possible future changes (cultural, societal and environmental), each accompanied by a dialogous creative response.

The disciplinary and creative works gathered here seek to explore the communicative possibilities of interdisciplinary encounters between researchers in a specific discipline and creative practitioners. These dialogous engagements offer powerful possibilities for negotiating the gap between the production of researched 'knowledge' and the dissemination and acceptance of such 'knowledge' by the general public, providing multi-faceted languages for envisioning and understanding. It is worth noting that creative writers of the stature of Ian McEwan have made it their scholarly business to research within disciplines ordinarily beyond their comfort zone. In producing Solar (2009), a novel relating to climate change, McEwan engaged with scientists and artists on a Cape Farewell trip to the Arctic and 'swotted up to PhD level in Physics' (Cowley 2010, np) to address this complex subject matter.

We are aware that such dialogues with a sometimes unfamiliar or confronting topic may be a challenge for the creative writer and that genres do not easily accommodate one another. Yet both academic writer and creative writer face a similar dilemma - to be heard when the message is tough. James Bradley recently captured this condition eloquently when he observed: 
The climatologist James Hansen once said being a climate scientist was like screaming at people from behind a soundproof glass wall: being a writer concerned with these questions often feels frighteningly similar (2017).

Inter-disciplinary dialogue is a potent tool and can foster extraordinary responses. Original or 'hybrid' forms may create new meanings, sometimes requiring what Krauth (2016 p.2) refers to as 'Radical' writing, demanding that the writer defies convention and writes 'in such way that the accepted processes of writing and reading are called into question'. Linking critical and creative responses to interrogate topics and issues such as the future of handwriting, the future of work, of grief, of darkness, the fascinating world of fungi and diving deep into the sounds of the ocean with the resultant poetry this evokes, provides evidence of a powerful and creative dialogical praxis that challenges the limitations of Lakoff's 'framing'. These unique dialogues elicit a set of synergistic responses: exemplars such as forensic document analysis (Paul Westwood), strategic foresight (Ivana Milojević), astrophysics (Chris Power), the sociology of grief (Margaret Gibson), or the human geography of climate change (Patrick Nunn) therefore provoke ficto-critical reflection (Paul Williams, Gary Crew, Daniel Jukes), cli-fi (Jacques Barcia) and dystopic science fiction (Shelly Davidow). Watkins' short story trilogy is based on the future of grief, Chandler and Davis' collaborative response on the ecological future(s) of fungi, while Brock's is a poetic response to the sonics of the sea. All attempt the radical; all are evocative.

With respect for the wisdom of academic questioning, the virtues and draw-backs of dialogue itself are also under examination in this collection. We need to question how far we can go in pushing the boundaries of disciplines and genres, asking: can the reader 'join the dots' when presented with two quite different texts: one the provocation (sometimes highly academic); the other a creative response (sometimes playfully poetic)?

Such questions are part of the ongoing struggle to understand ourselves through the lens of future science and the arts. As Isaac Asimov observed: 'science gathers knowledge faster than society gathers wisdom. Isn't it up to us to make sure they catch up with each other?' (cited in OECD 2008 p. 2). Our task in this special issue is to move across a landscape that is empirically informed and creatively charged. Again, drawing on Bradley (2017), we would argue that:

Language and stories are our species' way of making sense of the world, of ordering its meanings in ways that make them comprehensible, manageable. This process isn't neutral, of course: some stories - the good ones - seek to show us the world as it is, insisting on complexity, on fidelity to what is.

We wish to see the communicative and creative possibilities of encounters that provoke such real-world sense-making (OECD 2008). The project is based on a 'fidelity to what is' but committed to emergence as a hallmark of both the anticipatory imaginary and creative thinking (Avraamidou and Osbourne 2009). Ultimately though, both provocateur and creative writer generate dialogue to express 'thoughts and feelings and impressions. Brief moments in time. The extraordinary you can find in the ordinary. A changing life in this fleeting, wheeling world' (Cowen 2015 p. 317). 


\section{Works cited}

Avraamidou, L \& J Osborne 2009 'The Role of Narrative in Communicating Science', International Journal of Science Education, 31 (12), 1683-1707.

Bradley, J 2017 'Writing on the Precipice', Sydney Review of Books, at: https://sydneyreviewofbooks.com/writing-on-the-precipice-climate-change/ (accessed February 21, 2018)

Bussey, M 2017a 'Anticipatory Aesthetics: New Identities and Future Senses', in Clammer, J \& AK Giri (eds) The Aesthetics of Development: Art, Culture and Social Transformation, 49-70, Palgrave Macmillan, New York

Bussey, M 2017b 'Anticipatory Aesthetics: the senses and the body in anticipatory theory and practice', in R Poli (ed), The Handbook of Anticipation, 1-14, Springer, Berlin

Castoriadis, C 1997 World in Fragments: Writings on Politics, Society, Psychoanalysis, and the Imagination (D. A. Curtis, trans.), Stanford University Press, Stanford, California

Cowen, R 2015 Common Ground: Encounters with Nature at the Edge of Life, Hutchinson, London

Cowley, J 2010 Solar by Ian McEwan The Guardian, March 21 at: https://www.theguardian.com/books/2010/mar/14/solar-ian-mcewan, (acessed April 21, 2018)

Dickens, C 1859 A Tale of Two Cities, Chapman and Hall, London

Lakoff, G 2005 Don't Think of an Elephant: Know your values and frame the debate, Scribe Short Books, Melbourne

OECD 2008 Improving the Dialogue with Society on Scientific Issues, at: https://www.oecd.org/sti/scitech/42887346.pdf

Ricatti, F 2013 'The Emotion of Truth and the Racial Uncanny: Aborigines and Sicilians in Australia', Cultural Studies Review, 19 (2), 125-149

Sardar, Z 2010 'Welcome to Postnormal Times', Futures, 42 (5), 435-444 